Ensar, F. ve Gündüz, A. (2022). Öğretmen adaylarının psikolojik sağlamlıklarının topluluk önündeki konuşma kaygılarıyla ilişkisi. Ana Dili Eğitimi Dergisi, 10(1), 266-276.

Ana Dili Eğitimi Dergisi
Journal of Mother Tongue Education
www.anadiliegitimi.com
Geliş/Received: 01.06 .2021 Kabul/Accepted: 25.01 .2022
Araştırma Makalesi / Research Paper

\title{
Öğretmen Adaylarının Psikolojik Sağlamlıklarının Topluluk Önündeki Konuşma Kaygılarıyla ilişskisi* $^{*}$
}

\author{
Ferhat Ensar** \\ Abdurrahman GÜNDÜZ $Z^{* * *}$
}

\begin{abstract}
Öz
Bu araştırmanın amacı, öğretmen adaylarının psikolojik sağlamlık düzeylerinin topluluk önündeki konuşma kaygılarıyla olan ilişkisini incelemektir. Araştırma, nicel türde korelasyonel desende yürütülmüştür. Veriler, kolay ulaşılabilir durum örneklemesiyle belirlenmiş, Bartın ve Yıldız Teknik Üniversitesinde öğrenim gören 239 (kadın=174, erkek=65) öğretmen adayından elde edilmiştir. Veri toplama aracı olarak Kısa Psikolojik Sağlamlık Ölçeği (Doğan, 2015) ve Topluluk Önünde Konuşma Kaygısı Ölçeği (Doğru-Çabuker, Balcı-Çelik ve Aldemir, 2020) kullanılmıştır. Psikolojik sağlamlığın topluluk önünde konuşma kaygısını yordaması amacıyla yapılan basit doğrusal regresyon analizinde, iki değişken arasında anlamlı bir ilişki $\left(R=.309, R^{2}=.096\right)$ olduğu belirlenmiş ve psikolojik sağlamlığın topluluk önünde konuşma kaygı düzeyinin anlamlı bir yordayıcısı olduğu görülmüştür $[F(1-237)=25.026, p<.05]$. Bu açıdan psikolojik sağlamlık olgusunun, topluluk önünde yaşanan konuşma kaygısının doğasını anlamamıza katkı sağlayabilecek türden bir bilgi çerçevesi olduğu söylenebilir.
\end{abstract}

Anahtar Kelimeler: Psikolojik sağlamlık, topluluk önünde konuşma kaygısı, öğretmen adayları

\section{The Relationship between Pre-Service Teachers' Resilience and Public Speaking Anxiety}

\begin{abstract}
The purpose of this study is to examine the relationship between pre-service teachers' resilience levels and their public speaking anxiety. The study is quantitative by nature and uses a correlational design. The participants were 239 (female=174, male=65) pre-service teachers studying at two different universities who were selected via easily accessible sampling. The Brief Resilience Scale (Doğan, 2015) and the Public Speaking Anxiety Scale (Doğru-Çabuker, et al., 2020) were used as the data collection tools. In the simple linear regression analysis performed to predict public speaking anxiety in terms of resilience, a significant relationship $\left(R=.309, R^{2}=.096\right)$ was found between the two variables, and resilience was a significant predictor of public speaking anxiety $[F(1-237)=25.026, p<.05]$. It is thus clear that resilience is a type of information framework that can contribute to our understanding of the nature of public speaking anxiety.
\end{abstract}

Keywords: Resilience, public speaking anxiety, pre-service teachers

\footnotetext{
* Bu araştırma, 10-11 Aralık 2021 tarihinde 7. Uluslararası Marmara Sosyal Bilimler Kongresi'nde sözlü bildiri olarak sunulmuştur./ This research was presented as an oral presentation at the 7th International Marmara Social Sciences Congress on 10-11 December 2021.

** Doç Dr.; Bursa Uludağ Üniversitesi, Eğitim Fakültesi, Türkçe ve Sosyal Bilimler Eğitimi, e-posta: ferhatensar@uludag.edu.tr, ORCID: https://orcid.org/0000-0002-5282-2685

*** Doktora Öğrencisi, Uludağ Üniversitesi, Eğitim Fakültesi, Türkçe ve Sosyal Bilimler Eğitimi, e-posta: abdurrahman_gunduz@hotmail.com, ORCID: https://orcid.org/0000-0002-4447-3243
} 


\section{Giriş}

Üniversite öğrencilerinde yaygın olarak gözlemlenen (TÖKK) topluluk önünde konuşma kaygısına (Marinho, Medeiros, Lima, Pantuza ve Teixeira, 2019; Tillfors ve Furmark, 2006) konuşmacı ve dinleyiciden kaynaklanan faktörlerin neden olduğu bildirilmektedir (Muallimoğlu, 2011). Dinleyicinin; eğitim düzeyi (Gufriyansyah ve Khairani, 2019), uzman olması (Gündüz ve Şimşek, 2014), birden fazla olması (King, 1998) ve tanıdık olması (Baucom, 1994) konuşmacının kaygı düzeyini artıran dinleyici kaynaklı etmenler olarak değerlendirilmektedir. Deneyimsizlik (Carnegie, 1996; Tunalı, 2007), olumsuz düşünme (Condrill ve Bough; Esposito, 2010) ve yetersiz uygulama yapılması (İşcan ve Karagöz, 2016) ise konuşmacıdan kaynaklı konuşma kaygı düzeyini artıran etmenler olarak görülmektedir. Bunlarla birlikte, duygusal zekâ (Gündüz, 2020), genel öz-yeterlik algısı (Arslan, Ilıman ve Aslan, 2019), yaşam becerileri (Çodur, 2019), sesini tiz ya da yumuşak algılama (Marinho, Medeiros, Gama ve Teixeira, 2017), konuşma becerisine yönelik tutum (Tekşan, Mutlu ve Çinpolat, 2019), benlik saygısı, irrasyonel inanç ve sosyal onay (Şahan ve Kâhtalı, 2021), hazırlık (Menzel ve Carell, 1994) ve kişilik özellikleri (MacIntyre ve Thivierge, 1995) ile konuşma kaygısı arasında anlamlı ilişkiler olduğunu düşündüren faktörler de konuşmacıdan kaynaklı konuşma kaygı düzeyini etkileyen etmenler olarak sıralanmaktadır.

Kaygı kavramını konu edinen yakın dönem araştırmalarında psikolojik sağlamlık (PS) olgusu karşımıza çıkmaktadır. PS; kaygı (Açıkgöz, 2019; Baykal 2020; Çutuk, Beyleroğlu, Hazar, Çutuk ve Bezci, 2017; Hjemdal, Vogel, Solem, Hagen ve Stiles, 2011; İsaoğlu ve Tuzcuoğlu, 2021; Kasapoğlu, 2020; Kovács ve Borcsa, 2017; Kowalski ve Schermer, 2018; Min vd., 2013; Perişan, 2018), gelecek kaygısı (Dursun ve Özkan, 2019), işsizlik kaygısı (Taşğın, Bozgeyikli ve Boğazlıyan, 2017) ve sosyal kaygı (Işık ve Çelik, 2020; Ko ve Chang, 2019; Yngve, 2016) açılarından ilişkisel araştırmalara konu edilmiştir.

Uzun yıllardan bu yana akademik araştırmaların gündeminde olan PS'nin (Cotu, 2018) tanımı bağlamında temel bir uzlaşıya rastlanılmamaktadır (Gizir, 2007). Bunda birbirinden farklı tanımlara kaynaklık eden çok çeşitli kuramların varlığııın, aynı insan davranışının farklı şekillerde kavramlaştırılabileceğine yönelik düşüncelere olanak sağlamasının rolü bulunmaktadır (Frew ve Spiegler, 2008). PS; "bireyin strese ve zorluklara uygun şekilde uyum sağlama yeteneği" (Grupta ve Kumar, 2015, s. 188), "psikososyal risk deneyimlerine karşı göreceli direnç" (Rutter, 1999, s. 119), "risk ve olumsuzluklara rağmen başarılı bir uyum" (Masten, 1994, s. 3) ve "genellikle olağanüstü koşullara uyum sağlayan, zorluklar karşısında olumlu ve beklenmedik sonuçlar elde eden bireyleri tanımlamak" gibi durumlar için kullanılmaktadır (Fraser, Richman ve Galinsky, 1999, s. 136). Buna göre, PS'nin tanımlarında risk, olumlu uyum sergileme ve koruyucu faktör üç temel bileşen olarak öne çıkmaktadır (Işık, 2016).

PS, kişinin zorluklarla başa çıkabilmesini kolaylaştırarak uyum yeteneğinin zayıflamasına izin vermediği gibi (Doğan, 2015; Özkan, 2021; Altundağ, 2013) onu, kaygının (İsaoğlu ve Tuzcuoğlu, 2021) ve stresin olumsuz yanlarından da korumaktadır (Zurita-Ortega, Chaco'n-Cuberos, Cofre-Bolados, Knox ve Muros, 2018). Ayrıca, PS düzeyi yüksek kişiler daha etkili iletişim kurarak karşılaştıkları problemlerin de üstesinden daha iyi gelebilmektedir (Öz ve Yılmaz, 2009). Bu nedenle PS seviyesi yüksek kişiler, güçlüklere ve olumsuzluklara karşı daha dirençli olacağından onların daha hızlı bir biçimde normal durum koşullarına geri döneceği söylenebilir.

Bu araştırmada kaygının gözlemlenme biçimlerinden olan TÖKK üzerine odaklanıldı ve bu odaklanmada açıklayıcı bir yönü olabileceği düşüncesiyle PS araştırmanın yordayıcısı olarak belirlendi. TÖKK ilişkili olguların bilinmesinin, bu bağlamda gözlemlenen kaygının doğasını anlamlandırmaya yönelik çabaları destekleyeceği düşünülmektedir. Alan yazında öğretmen adaylarının konuşma kaygılarının düzeyini belirleyen pek çok çalışma bulunmaktadır (Baki ve Karakuş, 2015; Deringöl, 2018; Durmuş ve Baş, 2016; Ercan-Güven, 2020; İşcan ve Karagöz, 2016; Lüle-Mert, 2015; Özkan ve Kinay, 2015; Suroğlu-Sofu, 2012; Şen, 2017; Temiz, 2013, 2015; Tolun ve Güvey-Aktay, 2020). Öğretmen adaylarının örneklemini oluşturduğu konuşma kaygısı konulu ilişkisel araştırmalarda "kültürel zekâ (Kartal, 2019), "yaşam becerisi" (Çodur, 2019), "mesleğe yönelik tutum" (Özdemir, 2019) ve "etkili konuşma becerisi" (Baki ve Kahveci, 2017) gibi değişkenler incelenmiştir. Bunlarla birlikte "hazırlıklı konuşma" (Özdemir, 2018), "akran ve öğretmen geri bildirimi" (Hasırcl, 2018) ve "sözlü anlatım 
dersindeki çeşitli uygulamalar" (Katrancı ve Kuşdemir, 2015) gibi değişkenler açısından da öğretmen adaylarındaki konuşma kaygısının konu edildiği deneysel çalışmalar bulunmaktadır. Ancak, PS ile TÖKK arasında herhangi bir ilişkisel araştırmaya rastlanılmamıştır. Bu durumun bu araştırmanın önem derecesini artırdığı söylenebilir. PS'nin TÖKK ile bir ilişkisinin olup olmadığı belirlenmek amaçlandığından bu araştırma, nicel türde korelasyonel desen çerçevesinde yürütülmüştür. Bu amaç doğrultusunda bu araştırmada, öğretmen adaylarının psikolojik sağlamlık düzeylerinin topluluk önündeki konuşma kaygılarını anlamlı olarak yordayıp yordamadığı sorusunun yanıtı aranmıştır.

\section{Araştırmanın Modeli}

\section{Yöntem}

Bu araştırma, PS ile TÖKK arasında ilişki olup olmadığını belirlemeyi amaçladığından nicel araştırma desenlerinden korelasyonel araştırma desenine göre yürütülmüştür. Korelasyonel desen, en az iki değişken arasındaki ilişkiyi açıklamaktadır (Karasar, 2019). Korelasyonel desenin yordayıcı ve açıklayıcı olarak iki tipi vardır (Creswell, 2020). Bu araştırmanın amacı PS'nin yordayıcılığını belirlemek olduğundan veriler bu açıdan değerlendirilmiştir.

\section{Örneklem}

Araştırmanın örneklemini, kolay ulaşılabilir durum örneklemesi yoluyla belirlenen, Yıldız Teknik ve Bartın Üniversitesi Eğitim Fakültesinde öğrenim görmekte olan 174 'ü kadın, 65'i erkek olmak üzere 239 öğretmen adayı oluşturmaktadır.

\section{Veri Toplama Araçları}

Bu araştırmada, Kısa Psikolojik Sağlamlık Ölçeği (KPSÖ) ile Topluluk Önünde Konuşma Kaygısı Ölçeği (TÖKKÖ) veri toplamak amacıyla kullanılmıştır.

\section{Kısa Psikolojik Sağlamlık Ölçeği}

Smith, Dalen, Wiggins, Tooley, Christoper ve Bernard (2008) tarafından geliştirilen KPSÖ’nün Türkçeye uyarlama, geçerlik ve güvenirlik çalışmaları Doğan (2015) tarafından yapılmıştır. Araştırma verileri, 186'ını kadın, 109'u erkek olmak üzere (ölçeğin uyarlanması sürecinde) 295 üniversite öğrencisinden toplanmıştır. "Hiç uygun değil" (1), "Uygun Değil" (2), "Biraz Uygun"(3), "Uygun" (4), "Tamamen Uygun" (5) biçiminde bir yanıtlama anahtarına sahip olan KPSÖ, 5'li likert tipinde bir ölçektir. Ölçekte toplam 6 madde yer almakta ve bu maddelerden 2, 4 ve 6 . maddeler tersten kodlanmaktadır. Açıklayııı faktör analizi (AFA) sonucunda toplam varyansın \%54.66'sını açıklayan tek boyutlu yapı elde edilmiştir. Ölçeğin iç tutarlık katsayı .83 olarak tespit edilmiştir. AFA'da ortaya konan yapı, doğrulayıcı faktör analizi (DFA) ile doğrulanmıştır $\left[\left(\chi^{2} / \mathrm{sd}(12.86 / 7)=1,83, \mathrm{NFI}=0.99, \mathrm{NNFI}=0.99\right.\right.$, $\mathrm{CFI}=0.99, \mathrm{IFI}=0.99, \mathrm{RFI}=0.97, \mathrm{GFI}=0.99, \mathrm{AGFI}=0.96, \mathrm{RMSEA}=0.05, \mathrm{SRMR}=0.03]$. Ölçüt bağıntılı geçerlik bağlamında KPSÖ ile Oxford Mutluluk Ölçeği (Hills ve Argyle, 2002), Ego Sağlamlığı Ölçeği (Block ve Kremen, 1996) ve Connor-Davidson Psikolojik Sağlamlık Ölçeği (Connor ve Davidson, 2003) arasında pozitif yönde ilişkiler bulunmuştur. KPSÖ’nün araştırmada kullanılması için araştırmacıdan eposta yolu ile izin alınmıştır.

\section{Topluluk Önünde Konuşma Kaygısı Ölçeği}

Bartholomay ve Houlihan (2016) tarafından geliştirilmiş olan TÖKKÖ'nün Türkçeye uyarlama çalışmaları Doğru-Çabuker, Balcı-Çelik ve Aldemir (2020) tarafından yapılmıştır. Veriler, 138'i kadın, 60'ı erkek olmak üzere 198 üniversite öğrencisinden elde edilmiştir. Ölçek; bilişsel, davranış̧ıı ve psikolojik faktörlerden oluşmaktadır. 16 maddeye sahip bu ölçeğin 4 maddesi tersten puanlanmaktadır. "Asla" (1), "Çok az" (2), "Kısmen "(3), "Çok" (4), "Aşırı derecede" (5) şeklinde yanıtlama anahtarına sahip olan TÖKKÖ, 5'li likert tipinde bir ölçektir. Ölçeğin genelinin .93, alt faktörlerden bilişsel .88, davranışsal .69 ve psikolojik .86 iç tutarlılık kat sayısına sahip olduğu belirlenmiştir. DFA'da rapor edilen uyum indekslerine bakıldığında önceki yapı doğrulanmıştır $(\chi 2=211.55, p<.000, \chi 2 / s d=2.18, \mathrm{GFI}=.88, \mathrm{IFI}$ $=.947, \mathrm{RMR}=.063 \mathrm{RMSEA}=.077$ ). Ölçeğin dil geçerliğini sağlamak amacıyla Türkçe ve İngilizce formları dolduran İngilizce Öğretmenliği bölümü öğrencilerinin verdiği yanıtlar arasındaki korelasyon .96 olarak 
belirlenmiştir. Ölçüt geçerliğini sağlamak amacıyla Olumsuz Değerlendirilme Korkusu Ölçeği (Çetin, Doğan ve Sapmaz, 2010) ile TÖKKÖ arasında pozitif yönde anlamlı ilişki belirlenmiştir. TÖKKÖ’nün araştırmada kullanılması için araştırmacılardan e-posta yolu ile izin alınmıştır.

\section{Verilerin Toplanması}

Araştırmanın örneklemini oluşturan öğretmen adaylarına veri toplama araçlarını ulaştırabilmek için Google e-form olanaklarından yararlanılmıştır. Pandemi koşullarında yüz yüze eğitime ara verildiğinden katılımcılara Google e-form gönderilme gereksinimi duyulmuştur. Ulaşılabilen sınıflardaki katılımcıların ölçeklere yanıt vermelerinden önce; araştırmanın konusu, araştırmadan hangi sonuçların beklenildiği, istenildiği anda yanıtlamanın bırakılabileceği ve yanıtların gizli tutulacağı gibi hususlarda onlara yazılı bir bilgilendirme de sunulmuştur. Dolayısıyla, araştırmaya gönüllü olarak katılan öğretmen adaylarının yanıtları analize dâhil edilmiştir. Ölçeklere verilen dönütler açısından herhangi bir eksiklik bulunmadığından araştırmadan çıkarılan katılımcı olmamıştır.

\section{Verilerin Analizi}

Veriler, SPSS 20.0 istatistik programı yolu ile analiz edilmeden önce KPSÖ’ye ve TÖKKÖ’ye ait verilere normallik testleri ve iç tutarlılık analizi yapılmıştır. Elde edilen iç tutarlılık seviyesinin yüksek olması (KPSÖ= .87, TÖKKÖ=.93) bu ölçeklere verilen yanıtların tutarlı olduğunu göstermektedir. Verilerin normal dağılıp dağımadığını kontrol etmek amacıyla merkezi eğilim ölçüleri, basıklık ve çarpıklık değerleri kontrol edilmiştir (KPSÖ: ortalama=3.05, medyan=3.00 $\bmod =3.00$, çarpıklık=.10, basıklık=-.16; TÖKKÖ: ortalama=2.85, medyan=2.75 mod=2.44, çarpıklık=.37, basıklık=-.40). Elde edilen verilerin normal dağıldığına yönelik izlenim oluşmuştur. Merkezi eğilim ölçülerinin birbirine yakın (Can, 2017) ve çarpıklık değerinin +1 ve -1 aralığında olması (Hair, Black, Babin ve Anderson, 2014) verilerin dağılımının normalliğini göstermektedir. Verilerin normal dağıldığına karar verildikten sonra PS'nin TÖKK'ün anlamlı bir yordayıcısı olup olmadığını belirlemek amacıyla basit doğrusal regresyon analizi gerçekleştirilmiştir.

\section{Geçerlik ve Güvenirlik}

Araştırmada, veri toplamak amacıyla kullanılan KPSÖ ve TÖKKÖ’ye ait geçerlik ve güvenirlik bilgileri, veri toplama araçları ile verilerin analizi başlıkları altında yer verilmiştir.

\section{Araştırma ve Yayın Etiği}

Bu çalışmada "Yükseköğretim Kurumları Bilimsel Araştırma ve Yayın Etiği Yönergesi" kapsamında uyulması belirtilen tüm kurallara uyulmuştur. Yönergenin ikinci bölümü olan "Bilimsel Araştırma ve Yayın Etiğine Aykırı Eylemler" başlığı altında belirtilen eylemlerden hiçbiri gerçekleştirilmemiştir.

\section{Etik Kurul izni}

Kurul adı =Bursa Uludağ Üniversitesi Sosyal ve Beşeri Bilimler Araştırma ve Yayın Etik Kurulu Karar tarihi= 29 Nisan 2021

Belge sayı numarası= 2021-04 oturum sayısı, 41 No'lu karar

\section{Bulgular}

PS'nin TÖKK'ün anlamlı bir yordayıcısı olup olmadığını belirlemek amacıyla basit doğrusal regresyon analizi gerçekleştirilmiştir. Elde edilen bulgu Tablo 2'de yer almaktadır:

Tablo 2.

PS ile TÖKK Arasında Basit Doğrusal Regresyon Analizi Sonucu

\begin{tabular}{clllll}
\hline TÖKK & $B$ & SHB & B & $t$ & $p$ \\
\hline Sabit & 3.795 & .196 & & 19.409 & .000
\end{tabular}




\begin{tabular}{llllll} 
Psikolojik sağlamlık & -.309 & .062 & -.309 & .5 .003 & .000 \\
\hline$n=239, R=.309, R^{2}=.096, F=25.026, p<.05$ & & & & \\
\hline$* * p<.01$
\end{tabular}

PS'nin topluluk önünde konuşma kaygısını yordaması amacıyla yapılan basit doğrusal regresyon analizinde iki değişken arasında anlamlı bir ilişki $\left(R=.309, R^{2}=.096\right)$ olduğu belirlenmiş ve PS'nin TÖKK'ün anlamlı bir yordayıcısı olduğu görülmüştür $[F(1-237)=25.026, p<.05]$. PS, konuşma kaygısı düzeyindeki değişimin \%10'unu açıklamaktadır. Regresyon denklemine esas yordayıcı değişkenin katsayısının (B=-.309) anlamlılık testi de, PS'nin anlamlı bir yordayıcı olduğunu göstermektedir $(p<05)$. Analiz sonucuna göre PS'nin TÖKK'ü yordayan regresyon denklemi şu biçimdedir: Topluluk önünde konuşma kaygı düzeyi= (-.309 x Psikolojik sağlamlık düzeyi) + 3.795.

\section{Tartışma ve Sonuç}

Bu nicel araştırma ile PS'nin TÖKK'ün anlamlı bir yordayıcısı olup olmadığını test etmek amaçlanmıştır. Bu amaç doğrultusunda gerçekleştirilen basit doğrusal regresyon analizi sonucunda PS'nin TÖKK'ün anlamlı bir yordayıcısı olduğu belirlenmiştir. Bu sonuç PS'nin, öğretmen adaylarının TÖKK sürecinde yaşadıkları güçlükleri azaltarak bu bağlamda onlarda oluşan baskının da giderilebilmesi için etkili olduğunu düşündürmektedir.

Elde edilen bu sonucun alan yazındaki bulgularla paralellikler taşıdığı söylenebilir (Açıkgöz, 2019; Baykal, 2020; Çutuk vd., 2017; Dursun ve Özkan, 2019; Hjemdal vd., 2011; Işık ve Çelik, 2020; İsaoğlu ve Tuzcuoğlu, 2021; Kasapoğlu, 2020; Ko ve Chang, 2019; Kovács ve Borcsa, 2017; Kowalski ve Schermer, 2018; Perişan, 2018; Sahu, Gandhi, Sharma ve Marimuthu, 2019; Sood, Prasad, Schroeder ve Varkey, 2011; Yngve, 2016). Bu söylemin, psikolojik sağaltımın farkıı bir türü ve psikolojik işleyişin, insan gelişiminin bir modeli durumundaki PS olgusunun temel ilkelerine gönderimde bulunmayı kolaylaştıracağı da açıktır. Bu çerçevede alan yazın gözden geçirildiğinde PS'nin, TÖKK ile ilişkisini doğrudan ele alan bir çalışmaya rastlanılmamıştır. Fakat, kaygının farklı görünümleriyle olan ilişkisine gönderim yapıldığı örneklerin fazlaca olduğu görülmüştür. Örneğin, PS ile kaygı (Baykal, 2020; Çutuk vd., 2017; Hjemdal vd., 2011; İsaoğlu ve Tuzcuoğlu, 2021; Kasapoğlu, 2020; Kovács ve Borcsa, 2017; Kowalski ve Schermer, 2018), gelecek kaygısı (Dursun ve Özkan, 2019), işsizlik kaygısı (Taşğın vd., 2017), sosyal kaygı (Işık ve Çelik, 2020; Ko ve Chang, 2019; Yngve, 2016) ve stres arasında (Sahu vd., 2019; Yalçın, 2013) negatif yönlü anlamlı bir ilişkiden söz edilmektedir.

Kişilerin kendilerini engelleyici eylemlerinin psikolojik doğasını çözümleyebilmesi için PS'nin işlevsel bir rolünün bulunabileceği çıkarımından söz etmek olasıdır. Aynı zamanda bu çıkarım PS'yi hem kaygı giderimi için değişim hem de engelleyici davranış örüntüleri için bir anlamlandırma olgusu olarak karşımıza çıkarmaktadır. Alan yazında da PS eğitimi alan bireylerin kaygı düzeylerinde anlamlı bir azalma olduğu değerlendirilmekte (Sood vd.,2011) ve bu çerçevede PS'nin kaygının (Açıkgöz, 2019; Perişan, 2018) anlamlı bir yordayıcısı olduğu bildirilmektedir. Bu bildirimler içerisinden sosyal kaygı bulgusunun araştırma sonucumuzla daha yakın ilişkileri bulunduğu söylenebilir. Nitekim, topluluk önünde konuşma kaygısı sosyal kaygının bir belirtisi (Berksun, 2003; Dilbaz, 2000; Gruber ve Heimberg, 2016) olarak da değerlendirilmektedir. Ne var ki, pek çok araştırmacının topluluk önünde çeşitli konuşma sorunları yaşayan kişilere yönelik bilgisi, klasik yaklaşımların ötesine pek geçmemektedir. Oysa, psikoloji bilimi kaynaklı uygulamalarda epeyce değişiklikler yaşanmıştır. Sosyal davranışın gözlemlenme biçimi üzerine gerçekleştirilen çalışmalardaki yaklaşımlar da bu değişimlerle uyumlu olarak gelişmiştir. Bu nedenle sosyal davranışın bir görünümü durumundaki konuşma kaygısını topluluk önünde çeşitli konuşma problemleri yaşayan öğretmen adayları üzerinden irdelemenin, sözü edilen problemin kavramsal fikirlerin derinliği ve modern psikoloji uygulamaları ışığında nasıl bir evrim geçirdiğini de anlamamız açısından işlevsellik içerdiği söylenebilir.

Topluluk önünde çeşitli konuşma problemleri yaşayan öğretmen adaylarının (Akkaya, 2012; Başaran ve Erdem, 2009) konuşma kaygısını düşük düzeyde deneyimledikleri bildirilmektedir (Deringöl, 2018; Ercan-Güven, 2020; Lüle-Mert, 2015; Şen, 2017, Temiz, 2013, 2015; Tolun ve Güvey-Aktay, 2020). Öğretmen adaylarının konuşma kaygısını düşük düzeyde deneyimlemesinde PS olgusu dışındaki 
farklı değişkenlerin rolünün de belirlenmesi önemlidir. Öte yandan, konuşma becerisi dışındaki dil becerileri için de deneyimlenmesi olası kaygının PS ile ilişkisinin test edilmesi alan yazına katkı sunabilir. Ayrıca bu yönlü bir yaklaşımın bu araştırma örneğinde gözden geçirilmesi, pek çok sayıdaki psikolojik açıklamanın bir yansıması olan strateji ve örneklemelerin topluluk önünde çeşitli konuşma problemleri yaşayan öğretmen adayları için neden hala çağdaş bir problem çözme modeli olarak düşünülmesi gerektiğine ilişkin varsayımlara da destek kazandıracaktır

\section{Araştırma ve Yayın Etiği}

Bu çalışmada "Yükseköğretim Kurumları Bilimsel Araştırma ve Yayın Etiği Yönergesi" kapsamında uyulması belirtilen tüm kurallara uyulmuştur. Yönergenin ikinci bölümü olan "Bilimsel Araştırma ve Yayın Etiğine Aykırı Eylemler" başlığı altında belirtilen eylemlerden hiçbiri gerçekleştirilmemiştir.

\section{Etik Kurul izni}

Kurul adı =Bursa Uludağ Üniversitesi Sosyal ve Beşeri Bilimler Araştırma ve Yayın Etik Kurulu Karar tarihi= 29 Nisan 2021

Belge sayı numarası= 2021-04 oturum sayısı, 41 No'lu karar

\section{Yazarların Katkı Oranı}

Bu araştırmaya, birinci yazar \%50, ikinci yazar $\% 50$ oranında katkı sağlamıştır.

\section{Çıkar Çatışması}

Bu araştırmada çıkar çatışması teşkil edebilecek herhangi bir durum ve ilişki yoktur.

\section{Destek ve Teşekkür}

Araştırmaya katılımlarıyla katkı sunan katılımcılara teşekkür ederiz.

\section{Kaynaklar}

Açıkgöz, S. C. (2019). Depresyon, panik bozukluk ve yaygın anksiyete bozukluğunun psikolojik sağlamlık/dayanıklıık ile ilişkisi (Yayımlanmamış yüksek lisans tezi). İstanbul Okan Üniversitesi Sosyal Bilimler Enstitüsü, İstanbul.

Akkaya, A. (2012). Öğretmen adaylarının konuşma sorunlarına ilişkin görüşleri. Mustafa Kemal Üniversitesi Sosyal Bilimler Enstitüsü Dergisi, 9(20), 405-420.

Altundağ, Y. (2013). Anne-babası boşanmış ergenlerin psikolojik dayanıklılık düzeylerinde yordayıcı değişkenler olarak yaşam doyumu ve yalnızlık (Yayımlanmamış yüksek lisans tezi). Abant İzzet Baysal Üniversitesi Eğitim Bilimleri Enstitüsü Psikolojik Danışma ve Rehberlik Ana Bilim Dalı, Bolu.

Arslan, A., Ilıman, E. ve Aslan, R. (2019). Sağlık hizmetleri meslek yüksekokulu öğrencilerinin konuşma kaygıları ve öz-yeterlik algılarının çeşitli değişkenler açısından incelenmesi. Uluslararası Insan Çalışmaları Dergisi, 2(4), 124-147. DOI: 10.35235/uicd.526073

Baki, Y. ve Karakuş, N. (2015). A research on speech anxiety of prospective Turkish teachers. The Anthropologist, 1-2, 271-276.

Baki, Y. ve Kahveci, G. (2017). Türkçe öğretmeni adaylarının konuşma kaygılarının etkili konuşma becerileri üzerindeki etkisi: Bir yapısal eşitlik modellemesi. Turkish Studies, 12(4), 47-70.

Bartholomay, E. M., and Houlihan, D. D. (2016). Public speaking anxiety scale: Preliminary psychometric data and scale validation. Personality and Individual Differences, 9(4),211-215. DOI: 10.1016/j.paid.2016.01.026

Başaran, M. ve Erdem, İ. (2009). Öğretmen adaylarının güzel konuşma becerisi ile ilgili görüşleri üzerine bir araştırma. Kastamonu Eğitim Dergisi, 17(3), 743-754. 
Baucom, J. A. (1994). An exploratory study of public speaking anxiety and audience familiarity (Unpublished doctoral dissersation). California School of Professional Psychology, Berkeley, Alameda.

Baykal, E. (2020). COVID-19 bağlamında psikolojik dayanıklılık, kaygı ve yaşam doyum ilişkisi. International Journal of Social and Economic Sciences, 10(2), 68-80.

Berksun, O. (2003). Anksiyete ve anksiyete bozuklukları (2. baskı). İstanbul: Turgut Yayıncılık.

Block, J., and Kremen, A. M. (1996). IQ and ego-resiliency: Conceptual and empirical connections and separateness. Journal of Personality and Social Psychology, 70(2), 349-361.

Carnegie, D. (1996). Etkili konuşma sanatı. (G. Yılmaz, Çev.). İstanbul: Alkım.

Can, A. (2017). SPSS ile bilimsel araştırma sürecinde nicel veri analizi. (5. baskı). Ankara: Pegem Akademi Condrill, J. ve Bough, B. (2004). 101 iletişim yolu. (A. Şahin, Çev.) İstanbul: Beyaz Yayınları.

Connor, K. M., and Davidson, J. R. (2003). Development of a new resilience scale: The Connor Davidson Resilience Scale (CD-RISC). Depression and Anxiety, 18, 76-82.

Cotu, D. (2018). Duygusal esneklik nedir? (L. Göktem, Çev.). Duygusal Zekâ: Resillience içinde (s.7-39 Optimist Yayınevi: İstanbul.

Creswell, J. W. (2020). Eğitim araştırmaları. İstanbul: EDAM Eğitim Danışmanlığı ve Araştırmaları Merkezi.

Çetin, B., Doğan, T. ve Sapmaz, F. (2010). Olumsuz değerlendirilme korkusu ölçeği kısa formunun Türkçe uyarlaması: Geçerlik ve güvenirlik çalışması. Eğitim ve Bilim, 35(156), 205-216.

Çodur, H. (2019). Farklı programlardaki öğretmen adaylarının konuşma kaygı düzeyleri ile yaşam becerileri arasındaki ilişkinin fiziksel aktiviteye katılım ve farklı değişkenler açısından incelenmesi: Atatürk Üniversitesi örneği. (Yayımlanmamış yüksek lisans tezi). Atatürk Üniversitesi Kış Sporları ve Spor Bilimleri Enstitüsü Beden Eğitimi ve Spor Öğretmenliği Anabilim Dalı Beden Eğitimi ve Spor Eğitimi Bilim Dalı, Erzurum.

Çutuk, S., Beyleroğlu, M., Hazar, M., Çutuk, Z. A. ve Bezci, Ş. (2017). Judo sporcularının psikolojik dayanıklılık düzeyleri ile kaygı düzeyleri arasındaki ilişkinin incelenmesi. Beden Eğitimi ve Spor Bilimleri Dergisi, 11(1), 109-117.

Deringöl, Y. (2018). Sınıf öğretmeni adaylarının konuşma kaygıları. Manisa Celal Bayar Üniversitesi Sosyal Bilimler Dergisi, 16(3), 23-35. DOI: 10.18026/cbayarsos.465705.

Dilbaz, N. (2000). Sosyal anksiyete bozukluğu: Tanı, epidemiyoloji, etiyoloji, klinik ve ayırıcı tanı. Klinik Psikiyatri Dergisi 3(2), 3-21

Doğan, T. (2015). Kısa psikolojik sağlamlık ölçeği'nin Türkçe uyarlaması: Geçerlik ve güvenirlik çalışması. The Journal of Happiness and Well-Being, 3(1), 93-102.

Doğru-Çabuker, N. , Balcı-Çelik, S. ve Aldemir, A. (2020). Topluluk önünde konuşma kaygısı ölçeğinin Türkçeye uyarlanması: Geçerlik ve güvenirlik çalışması. Elektronik Sosyal Bilimler Dergisi, 19 (76), 1601-1610. DOI: 10.17755/esosder.674060

Dursun, A. ve Özkan, M. S. (2019). Ergenlerin gelecek kaygıları ile psikolojik sağlamlıkları arasındaki ilişkide yaşam doyumunun aracı rolü. Yaşam Becerileri Psikoloji Dergisi, 3(5), 23-37.

Durmuş, E. ve Baş, K. (2016). Sosyal bilgiler öğretmen adaylarının konuşma kaygılarının incelenmesi. Turkish Studies, 11(19), 325-336. DOI: 10.7827/TurkishStudies.9981.

Ercan-Güven, A. N. (2020). Öğretmen adaylarının anlatma becerilerine yönelik kaygı düzeylerinin incelenmesi. Eğitim Kuram ve Uygulama Dergisi, 6(2), 174-188. DOI: 10.38089/ekuad.2020.12

Esposito, J. (2010). Sahne ışıkları altında: Topluluk önünde konuşma ve performans sergilemeyle ilgili korkularınızdan kurtulun (K. Önem, Çev.). İstanbul: Elips Kitap.

Fraser, M. W., Richman, J. M., and Galinsky, M. J. (1999). Risk, protection, and resilience: Toward a conceptual framework for social work practice. Social Work Research, 23(3), 131-143. DOI: 10.1093/swr/23.3.131

Frew, J. ve Spiegler, M. (2008). Contemporary psychotherapies for a diverse world. Boston, MA: Lahaska Press.

Gizir, C. A. (2007). Psikolojik sağlamlık, risk faktörleri ve koruyucu faktörler üzerine bir derleme çalışması. Türk Psikolojik Danışma ve Rehberlik Dergisi, 3(28), 113-128. 
Gruber, K. ve Heimberger, R. G. ( 2016). Sosyal anksiyete için bir bilişsel-davranış̧̧ı terapi paketi. W. T. Roth ve I.D. Yalom (Ed.), Anksiyete terapisi içinde (s.287-323). İstanbul: Prestij Yayınları.

Grupta, N. and Kumar, S. (2015). Significant predictors for resilience among a sample of undergraduate students: Acceptance, for-giveness and gratitude. Indian Journal of Health and Wellbeing, 6(2), 188-191.

Gufriyansyah, R., and Khairani, M. (2020). An experiment of public speaking anxiety oncollege students. In Proceedings of the 1st International Conference on Psychology (ICPsy 2019), 51.DOI: $10.5220 / 0009433900050011$

Gündüz, A. (2020). Duygusal zekâ ile konuşma kaygısı arasındaki ilişki (Yayımlanmamış yüksek lisans tezi). Fırat Üniversitesi Eğitim Bilimleri Enstitüsü Türkçe ve Sosyal Bilimler Eğitimi Anabilim Dalı Türkçe Eğitimi Bilim Dalı, Elazığ.

Gündüz, O. ve Şimşek, T. (2014). Uygulamalı konuşma eğitimi el kitabı. Ankara: Grafiker Yayınları.

Hair, J. F. Jr., Black, W. C., Babin, B. J., and Anderson, R. E. (2014). Multivariate data analysis (7th ed.). Pearson Education: Upper Saddle River.

Hasırcı, S. (2018). Türkçe öğretmeni adaylarının konuşma kaygıları üzerindeki etkisi açısından akran ve öğretmen geribildirimi. Turkish Studies, 13(4), 685-706

Hills, P., and Argyle, M. (2002). The Oxford happiness questionnaire: A compact scale for the measurement of psychological well-being. Personality and Individual Differences, 33, 10731082.

Hjemdal, O., Vogel, P. A., Solem, S., Hagen, K., and Stiles, T. C. (2011). The relationship between resilience and levels of anxiety, depression, and obsessive-compulsive symptoms in adolescents. Clinical psychology and Psychotherapy, 18(4), 314-321.

Işık, ş. (2016). Türkiye'de kendini toparlama gücü konusunda yapılmış araştırmaların incelenmesi. Turkish Psychological Counseling and Guidance Journal, 6(45), 65-76.

Işık, Y. ve Çelik, E. (2020). Ergenlerde psikolojik sağlamlığın sosyal dışlanma, sosyal kaygı, cinsiyet ve sınıf düzeyi açısından incelenmesi. OPUS Uluslararası Toplum Araştırmaları Dergisi, 16(27), 174-209. DOI: 10.26466/opus.642037

İsaoğlu, J. ve Tuzcuoğlu, A. (2021). Suriye uyruklu üniversite öğrencilerinde psikolojik dayanıklılık, yalnızlık ile kaygı arasındaki ilişkide bilişsel üçlünün aracı rolü. Marmara Üniversitesi Atatürk Eğitim Fakültesi Eğitim Bilimleri Dergisi, 53(53), 399-424. DOI: 10.15285/maruaebd.731606

İşcan, A. ve Karagöz, B. (2016). Türkçe öğretmeni adaylarının konuşma kaygılarının incelenmesi (Gaziosmanpaşa Üniversitesi örneği). Ahi Evran Üniversitesi Kırşehir Eğitim Fakültesi Dergisi, 17(3), 193-206.

Karasar, N. (2019). Bilimsel araştırma yöntemi: Kavramlar ilkeler teknikler (34. basım). Ankara: Nobel.

Kasapoğlu, F. (2020). COVID-19 salgını sürecinde kaygı ile maneviyat, psikolojik sağlamlık ve belirsizliğe tahammülsüzlük arasındaki ilişkilerin incelenmesi. Turkish Studies, 15(4), 599-614. DOI: 10.7827/TurkishStudies.44284

Kartal, M. (2019). Beden eğitimi ve spor bölümü öğretmen adaylarının konuşma kaygısı ve kültürel zekâ arasındaki ilişkinin incelenmesi (Yayımlanmamış yüksek lisans tezi). Ondokuz Mayıs Üniversitesi Sağlık Bilimleri Enstitüsü Beden Eğitimi Öğretmenliği Anabilim Dalı, Samsun.

Katrancı, Y. ve Kuşdemir, M. (2015). Öğretmen adaylarının konuşma kaygılarının incelenmesi: Sözlü anlatım dersine yönelik bir uygulama. Dicle Üniversitesi Ziya Gökalp Eğitim Fakültesi Dergisi, $24,415-445$. DOI: 10.14582

King, L. (1998). Kiminle, ne zaman, nerede, nasıl konuşmalı? (Y. Özdemir-Bradley, Çev.). İnkılap Kitapevi: İstanbul.

Ko, C.-Y. A., and Chang, Y. (2019). Investigating the relationships among resilience, social anxiety, and procrastination in a sample of college students. Psychological Reports, 122(1), 231-245. DOI: $10.1177 / 0033294118755111$

Kovács, I. K. and Borcsa, M. (2017). The relationship between anxiety, somatic symptoms and hardiness inadolescence. Romanian Journal of Applied Psychology, 19(2), 42-49. 
Kowalski, C. M. and Schermer, J. A. (2018). Hardiness, perseverative cognition, anxiety, and healthrelated outcomes: A case for and against psychological. Psychological Reports, 122(6), 1-23. DOI:10.1177/003.329.4118800444

Lüle-Mert, E. (2015). Türkçe öğretmeni adaylarının konuşma kaygılarına ilişkin bir inceleme. Uluslararası Sosyal Araştırmalar Dergisi, 8(37), 784-789.

Maclntyre, P. D., and Thivierge, K. A. (1995). The effects of speaker personality on anticipated reactions to public speaking anxiety. Communication Research Reports, 12(2), 125-133.

Marinho, A. C. F., de Medeiros, A. M., Gama, A. C. C. ve Teixeira, L. C. (2017). Fear of public speaking: Perception of college students and correlates. Journal of Voice, 31(1), 127-e7. DOI: 10.1016/j.jvoice.2015.12.012.

Marinho, A.C., Medeiros, A.M., Lima, E.D., Pantuza, J.J., and Teixeira, L.C. (2019). Prevalence and factors associated with fear of public speaking. CoDAS, 31(6), e20180266. DOI: 10.1590/2317$1782 / 20192018266$

Masten, A. S. (1994). Resilience in individual development: Successful adaptation Despite risk and adversity. In Wang, M. C. and Gordon, G. W. (Eds.), Educational resilience in inner city America: Challenges and prospects (pp. 3-25) New Jersey: Lawrence Erlbaum Associates, Inc.

Menzel, K. E. and Carrell, L. J. (1994). The relationship between preparation and performance in public speaking. Communication Education, 43(1), 17-26.

Min, J. A., Jung, Y. E., Kim, D. J., Yim, H. W., Kim, J. J., Kim, T. S., ... and Chae, J. H. (2013). Characteristics associated with low resilience in patients with depression and/or anxiety disorders. Quality of Life Research, 22(2), 231-241

Muallimoğlu, N. (2011). Bütün yönleriyle hitabet: konuşma sanatı (8. baskı). İstanbul: Avcıol Basım Yayın.

Perişan, N. (2018). Kaygı, psikolojik dayanıklılık ve başa çıkma yolları arasındaki ilişki: üst bilişin aracı rolü (Yayımlanmamış yüksek lisans tezi). Sosyal Bilimler Enstitüsü Maltepe Üniversitesi, ìstanbul.

Rutter, M. (1999). Resilience concepts and findings: Implications for family therapy. Journal of Family Therapy, 21, 119-144.

Sahu, M., Gandhi, S., Sharma, M. K., and Marimuthu, P. (2019). Perceived stress and resilience and their relationship with the use of mobile phone among nursing students. Investigacion $y$ educacion en enfermeria, 37(3), e05. DOI: 10.17533/udea.iee.v37n3e05

Smith, B. W., Dalen, J., Wiggins, K., Tooley, E., Christopher, P., and Jennifer-Bernard, J. (2008). The brief resilience scale: Assessing the ability to bounce back. International Journal of Behavioral Medicine, 15, 194-200.

Sood, A., Prasad, K., Schroeder, D. ve Varkey, P. (2011). Stress management and resilience training among Department of Medicine faculty: a pilot randomized clinical trial. Journal of General Internal Medicine, 26(8), 858-861

Suroğlu-Sofu, M. (2012). Öğretmen adaylarının konuşma kaygıları (Yayımlanmamış yüksek lisans tezi). Sakarya Üniversitesi Eğitim Bilimleri Enstitüsü Türkçe Eğitimi Anabilim Dalı, Sakarya.

Şahan, B. and Kahtalı, B.D. (2021). The role of parental attitudes, irrational beliefs, need for social approval and self-esteem in speech anxiety. European Journal of Alternative Education Studies, 6(1),96-115. DOI: 10.46827/ejae.v6i1.3729

Şen, Ü. (2017). Türkçe öğretmeni adaylarının konuşma kaygılarının değerlendirilmesi. Uluslararası Türkoloji Araştırmaları ve incelemeleri Dergisi, 2(2) 70-84.

Taşğın, Ö., Bozgeyikli, H. ve Boğazlıyan, E. (2017). Üniversiteli gençlerin işsizlik kaygıları ile psikolojik dayanıklılıkları arasındaki ilişki. Hak iş Uluslararası Emek ve Toplum Dergisi, 6(16), 551-567.

Tekşan, K., Mutlu, H. H. ve Çinpolat, E. (2019). The examination of the relationship between the speech anxiety and speaking skill attitudes of middle school students and the opinions of teachers on speech anxiety. Journal of Language and Linguistic Studies, 15(4), 1395-1412. DOI: $10.17263 /$ jlls.668527

Temiz, E. (2013). Speech anxiety of music and Turkish language teacher candidates. Journal of Educational and Instructional Studies In The World, 3(2), 101-105. 
Temiz, E. (2015). Pedagojik formasyon alan öğretmen adaylarının konuşma kaygıları. Turkish Studies, 10(3), 985-992. DOI: 10.7827/TurkishStudies.7767.

Tillfors, M., and Furmark, T. (2007). Social phobia in Swedish university students: prevalence, subgroups and avoidant behavior. Social Psychiatry and Psychiatric Epidemiology, 42, 79-86. DOI: 10.1007/s00127-006-0143-2

Tolun, K. ve Güvey-Aktay, E. (2020). Sınıf öğretmeni adaylarının konuşma kaygıları. Eğitim Kuram ve Uygulama Araştırmaları Dergisi, 6(1), 86-98. DOI: 10.38089/ekuad.2020.5

Tunalı, M. (2007). Başarılı ve güzel konuşma sanatı (36. baskı). İstanbul: Yediveren Yayınları.

Öz, P. ve Yılmaz, E. B. (2009). Ruh sağlı̆̆ının korunmasında önemli bir kavram: psikolojik sağlamlık. Hacettepe Üniversitesi Hemşirelik Fakültesi Dergisi, 16(3), 82-89.

Özdemir, G. (2019). Sosyal bilgiler öğretmen adaylarının öğretmenlik mesleğine yönelik tutumları ile konuşma kaygı düzeyleri arasındaki ilişkinin tespit edilmesi: Niğde ili örneği (Yayımlanmamış yüksek lisans tezi). Niğde Ömer Halisdemir Üniversitesi Eğitim Bilimleri Enstitüsü Türkçe ve Sosyal Bilimler Eğitimi Ana Bilim Dalı Sosyal Bilgiler Eğitimi Bilim Dalı, Niğde.

Özkan, E. ve Kinay, í. (2015). Öğretmen adaylarının konuşma kaygılarının incelenmesi (Ziya Gökalp Eğitim Fakültesi Örneği). Uluslararası Türkçe Edebiyat Kültür Eğitim Dergisi, 4(3), 1290-1301.

Özkan, M.S. (2021). Psikolojik sağlamlık odaklı psiko-eğitim programının bir grup yetişkinin psikolojik sağlamlık, duygusal zekâ ve toplumsal ilgi düzeylerine etkisinin incelenmesi (Yayımlanmamış doktora tezi). Bursa Uludağ Üniversitesi Eğitim Bilimleri Enstitüsü Eğitim Bilimleri Ana Bilim Dalı Rehberlik Ve Psikolojik Danışmanlık Bilim Dalı, Bursa.

Yalçın, S. (2013). Ilköğretim okulu öğretmenlerinin mesleki tükenmişlik düzeyleri ile stres, psikolojik dayanıklıık ve akademik iyimserlik arasındaki ilişki (Yayınlanmamış yüksek lisans tezi). Gazi Üniversitesi Eğitim Bilimleri Enstitüsü, Ankara.

Yıldırım, G. (2015). Ortaokul öğrencilerinin konuşma kaygıları (Yayımlanmamış yüksek lisans tezi). Uşak Üniversitesi Sosyal Bilimler Enstitüsü, Uşak.

Yngve, A. (2016). Resilience against social anxiety: The role of social networks in social anxiety Disorder (master thesis). Access address: http://www.diva portal.org/smash/get/diva2:968637/ FULLTEXT01.pdf.

Zurita.-Ortega, F., Chaco'n-Cuberos, R., Cofre-Bolados, C., Knox E, Muros, J. J. (2018). Relationship of resilience, anxiety and injuries in footballers: Structural equations analysis. PLOS ONE, 13(11), e0207860. DOI: 10.1371/journal.pone.0207860

\section{Extended Abstract}

\section{Introduction}

Speaker and listener-related factors cause public speaking anxiety (Muallimoğlu, 2011) which is commonly observed in university students (Marinho, et al., 2019; Tillfors and Furmark, 2006). This study focused on resilience, which we think is related to public speaking anxiety caused by the speaker himself. Resilience enables people to overcome difficulties and the negative aspects of anxiety (isaoğlu and Tuzcuoğlu, 2021), helps them to adapt to difficult situations (Doğan, 2015; Özkan, 2021; Altundağ, 2013), and protects them from stress (Zurita-Ortega, et al., 2018). In addition, people with high psychological resilience communicate more effectively and cope better with the problems they encounter (Öz and Bahadır-Yılmaz, 2009).

Numerous studies that aimed to determine the level of speaking anxiety of teacher candidates (Baki and Karakuş, 2015; Deringöl, 2018; Durmuş and Baş, 2016; Ercan-Güven, 2020; İşcan and Karagöz, 2016; Lüle-Mert, 2015; Özkan and Kinay, 2015; Suroğlu-Sofu, 2012; Şen, 2017; Temiz, 2013, 2015; Tolun and Güvey-Aktay 2020) and identify the problems experienced in their speeches (Akkaya, 2012; Başaran and Erdem, 2009) exist in the literature. The current study aims to examine the relationship between resilience and public speaking anxiety of prospective teachers for there is no study that examines the relationship between resilience and public speaking anxiety. Thus, it is the first study in the literature that intends to examine this relationship. 


\section{Method}

This study is quantitative by nature and uses a correlational design. Correlational design is used to examine the relationship between at least two variables (Karasar, 2019). The correlational design has two types: predictive and explanatory (Creswell, 2020). This study employed the predictive correlational design because of its relevance to its focus.

The sample consisted of 239 pre-service teachers in two Turkish universities who were selected through easily accessible sampling. The participants were asked to take the Brief Resilience Scale (Doğan, 2015) and Public Speaking Anxiety Scale (Doğru-Çabuker, et al., 2020) online. A Google e-form was sent to the participants. The answers by the participants were included in the analysis. A simple linear analysis was carried out at the .05 significance level to determine whether resilience could predict public speaking anxiety.

\section{Results and Discussion}

The simple linear regression analysis showed that resilience was a significant predictor of public speaking anxiety. This result has parallels with the findings of different studies in the literature. Although no study directly addresses the relationship between resilience and public speaking anxiety in the literature, the relationship between resilience and different manifestations of anxiety has been addressed in various studies. The findings of those studies show that there is a closer relationship between the different forms of social anxiety and resilience as was found in the current study because public speaking anxiety is considered as a symptom of social anxiety (Berksun, 2003; Dilbaz, 2000; Gruber and Heimberg, 2016). Based on the results of this study, resilience appears as an information framework that can contribute to our understanding of the nature of public speaking anxiety. Studies dealing with the relationship between pre-service teachers' reading, listening, and writing anxiety and resilience would also contribute to the literature. 